\title{
Influence of Student Motivation by Teachers on Academic Performance in Public Secondary Schools in Nyeri and Kirinyaga Counties, Kenya
}

\author{
Mercy Gathoni Kariuki ${ }^{1}$, Zachariah Kariuki Mbugua ${ }^{1}$ \\ ${ }^{1}$ Karatina University, 1498, 10101 Karatina, KENYA \\ *Corresponding Author: muthomercy@gmail.com \\ Citation: Kariuki, M. G. and Mbugua, Z. K. (2018). Influence of Student Motivation by Teachers on \\ Academic Performance in Public Secondary Schools in Nyeri and Kirinyaga Counties, Kenya. Pedagogical \\ Research, 3(4), 14. https://doi.org/10.20897/pr/3947
}

Published: November 28, 2018

\begin{abstract}
Student motivation is an essential component that plays an instrumental role in their learning. Although academic motivation has received much conceptual and empirical focus, cases of high school students exhibiting lack of willingness to execute the academic tasks are rampant, leading to decline in performance at Kenya Certificate of Secondary Education. The objective was to determine teacher's related motivation factors influencing students' academic performance. A descriptive survey research design was used. The target population was 270 principals, 270 class teachers and 9980 students. Gay's formula of $10 \%$ was used to select 27 principals, purposively sample 27 class teachers and used Stratified sampling to select 27 schools. The table by Krejcie and Morgan was used to select 370 students and simple random sampling was applied. Questionnaires were used to gather the needed data. Data was analyzed with the help of SPSS version 19. Analyzed data was represented in table form. $68.5 \%$ of teachers and $64.3 \%$ of students agreed on expectations, $90.7 \%$ of teachers and $84.6 \%$ of students agreed that positive teacher-student relationship, $81.5 \%$ of the teachers and $86.5 \%$ of students agreed that rewards highly motivated students. The research concluded that student motivation by teachers has a positive influence on academic performance.
\end{abstract}

Keywords: academic performance, incentive, motivation

\section{INTRODUCTION}

In any school setting, a student's motivation for learning is considered among the most crucial determinants of the quality and success of any learning outcome (Mitchell, 1992). Unlike some of the other mental states or processes, motivation usually has an effect on almost all areas of a learning institution. The motivation of students relates to their desire to take part in the learning process. Additionally, it is also related to the goals or reasons that underlie in the student's involvement in academic undertakings. Even though learners may correspondingly be motivated to carry out a task, where they acquire motivation differs (Ngeno and Changeiywo, 2007). Elliot et al. (2005) noted that motivation is an important aspect for academic learning and success through childhood across adolescence. Accordingly they indicate that, motivation is a fundamental contributor to student success. Their study has also indicated that motivation is connected to a range of results like persistence, performance, curiosity and learning. Athman et al. (2004) argued that poor motivation among students adversely affects student performance. They positively indicated there is a connection between performance and motivation.

Deci et al. (2000) describes extrinsic motivation as, concerning a wide array of actions employed as a way to achieve an end goal and not for their own sake. They note that intrinsic motivation means taking part in a particular activity for itself, and the satisfaction and pleasure drawn from the involvement. The studies on the holistic and dynamic sensation of flow, aesthetic stimulating experiences, peak experiences and feelings of excitement in 
intrinsic motivation, is representation of this kind of intrinsic motivation (Ayub, 2010). While intrinsic motivation may be noticeably a fundamental form of motivation, a majority of the actions individuals carry out are not strictly intrinsically motivated. In fact, the situation following early childhood is where the freedom that is being motivated intrinsically is progressively truncated by social roles and requirements which necessitate people to adopt responsibility for none of the intrinsically interesting activities. As an example, in schools, it seems like intrinsic motivation gets weaker as the grades advance.

Extrinsic motivation refers to when an action is done with intention to obtain a separable outcome. Intrinsic motivation conversely is where an activity or action is done simply for the fulfillment derived from performing the activity itself rather than the instrumental value and therefore contrast with extrinsic motivation. While some views may suggest that behavior motivated extrinsically as invariantly autonomous, the Self-Determinant Theory posits that extrinsic motivation varies in the degree of autonomy greatly. An example of this is students who only do their homework because they fear parental repercussions if they don't. This is extrinsically motivated since they only do the homework to avoid punishment which is the separable outcome. Meanwhile, another learner may do the homework believing that it has a value towards their chosen career. They are also extrinsically motivated since they do the homework for its instrumental value and not because they find it captivating. The two examples involve instrumentalities. The latter case demonstrates a feeling of choice and personal choice while the latter involves an external control that forces compliance. Both cases and types of extrinsic motivation constitute intentional behavior but differ in their relative autonomy.

Integrated regulation is the most sovereign type of extrinsic motivation. When the identified regulations have been fully incorporated into the self that is when integration occurs. It occurs by merging new regulations with one's needs and values and through self-examination. When one increasingly internalizes the causes for a particular action or actions and adopts them, the greater the possibility of one's extrinsically motivated behaviors becoming self-determined. Intrinsic forms of motivation and integrated motivation share many qualities. Both are uncomplicated and autonomous. However, behavior motivated through integrated regulation is still extrinsic since it is carried out because of its presupposed instrumental value in relation to an outcome which is separate from the behavior despite it being volitional and important to the self.

Providing motivation is an essential aspect of teaching and learning. Baker et al. (2008) indicated that educators have an essential role in the direction students take all through their formal schooling. Since a larger part of the learning occurs inside the classrooms, McKinney (2000) described the classroom alterable variables as affecting the effectiveness of what takes place inside the four walls. These are the variables that can be altered in such a way that improvements can be made on student learning. Additionally, altering the variables can lead to the discovery of new learning conditions that enable a high learning standard for virtually every student. Psychologist note that when extrinsic motivation is used in excess it is likely to lead to hate, an over dependence on educators, limitation of transfer, compromise intrinsic motivation and also cause students to view learning as a means to an end (Covington, 2000). Psychologists suggest that teachers should only use extrinsic types of rewards if they bring about the desired and correct response so as to reduce the negative effects. The incentive or reward could be money, which is material, or an intangible one like a positive reaction from a notable person. From this position, motivation appears to be brought about by environmental or external cues instead of internal drivers. Even though external factors are the main stimuli when it comes to motivation the incentive theory, however, pushes an individual towards achieving an incentive goal by supporting the indirect role of intrinsic motivation.

Students learn best when their motives and incentives for learning are aligned. These motives may include, the intention to learn so that they can complete an activity, the basic need for new experiences, a need to perfect particular skills, to trounce a particular challenge, to be competent, a need to be successful, and also a need to interact with peers. Being able to satisfy these needs is rewarding and sustain learning more constructively than grades do. Motivation levels are extremely impacted by our environment (Mitchell et al., 2003). As educators, there are several environments that are out of one's control such as, the learners' home life, their social circles, and their workplaces. The teacher, however, has control over the learning environment where they have an opportunity to impact their learners' level of motivation immensely.

Wells (2011) research portrayed that positive self-concepts in students was improved by student-teacher relationships. Despite the situational condition, the support given by teachers was discovered to bring about goal motivations. Gallagher (2013) study claimed that the gender, social based differences articulated as culture in the society of South Africa, impacted negatively on the upholding of intrinsic motivation. The research also backs the notion that there is a need to integrate psycho-social development into the academic lives of students to achieve a holistic understanding and probably improve their academic performance. Findings in this research corresponded with other studies of resiliency, particularly among traditional African women.

Hamre and Pianta (2001) noted the classrooms usually become supportive spaces when there is a positive teachers-student bond. Students can, therefore, engage in socially and academically productive activities in these spaces. They indicate that some level of positivity, closeness and warmth among the students is established when 
the positive teacher-student relationship is present. They also note that in tackling academic challenges and in social-emotional development, students having relationships with their teachers that are positive have a more stable platform that allows them to study the school and classroom scenery both socially and academically. (Hamre and Pianta, 2001) indicate that this also incorporates relationships with peers, building self-concept and also building self-esteem. Murray and Malmgren (2005) argue that students get to learn about their academic expectations, socially appropriate behaviors and how to attain the academic expectations through these secure positive relationships. Positive relationships with teachers can be particularly beneficial to students in low-income schools. Migley et al. (1989) did a study on learners who were moving from elementary to middle school. These students had a high positive relationship with their teachers as they finalized elementary school, which had dropped to a less positive relationship with their teachers when at middle school. The study was to check on motivation and mathematics achievement. They discovered that there was a considerably decrease in the students' math skills, indicating a decrease in academic proficiency. Migley et al. (1989) also noted that the awareness of the presence of a caring teacher, impacted the academic achievement of those learners that are regarded as high risk for high school dropout. Furthermore, their study also noted that for those students who moved from elementary school that had low teacher-student closeness to middle school that had a high teacher-student closeness, considerably increased in their mathematical skills.

Murray and Malmgren (2005) noted that high-poverty learners are associated with low self-esteem in their academics and exhibit low confidence in their vocational and academic futures. Therefore, having positive teacherstudent relationships is critical in enhancing the students get better degrees of self-efficacy in their academics, selfesteem and higher confidence levels in their employment outcomes in the future (Wentzel, 2003). The interest of students in school, their efficacy in academics and their academic success is affected by their future aspirations and confidence (Wentzel, 2003). In addition, positive relationships between the teachers and students offer significant social effects for the students and are effective on the self-esteem in the academics of the students.

The teachers' expectations are recognized to have a key role in academic achievement. Therefore, understanding the link between the teacher's expectations and the academic performance of the students is crucial. Evidence derived from psychology experiments indicate that the teachers' expectations of students' abilities may influence consequent student academic performance (Tenenbaum et al., 2007). In these studies, experimenters manipulate teacher expectations through deception and typically find a positive correlation between teacher expectations and future academic success. While these studies are econometrically clean since changes in teacher expectations are exogenous, they have been criticized on methodological grounds for lacking external validity (Okagaki and Frensch, 2006) and have been contradicted by a growing body of experiments that fail to replicate these results (Quiocho et al., 2006). Moreover, there has been little credible research that examines the role of teacher expectations in non-experimental settings. Henry et al. (2012) indicated that the perception of student to the teacher's expectations was closely associated to motivation. From research on middle and high school students, it has also been noted that the students will mold their own academic expectations based on their perception on the teachers' expectations. Wentzel (2003) noted that students will perform better academically if they perceive that their teachers have high expectations from them. That is this high expectation by their teachers will make them feel motivated to perform better. Additionally, for those students who perceive that their teachers do not have high expectations for them, they will perform poorly. As a result of this effect of expectations on motivation, expectations can be identified as a vital factor on students' performance academically.

The education system in Kenya has been laying emphasis on performance as being an essential part of quality education as outlined in the 2005 sessional paper No.1 (MOEST, 2005). To realize the millennium development goal and the vision 2030, it is paramount to provide quality education that results in high performance in schools. Performance in K.C.S.E. determines whether students will proceed to university or other tertiary institutions. In Kenya the level of student's motivation has been cited as the key element in secondary school education (Miheso, 2012). Schools invest in inviting guests to speak to their learners with the aim of increasing the level of motivation in their learners. Kusereka (2003) noted that student motivation in Kenya is a component of home background, the school factors and the learner personality.

\section{OBJECTIVES}

The following objectives guided the study:

i. To establish whether positive teacher-student relationships influence the performance of students academically in public secondary schools in Nyeri and Kirinyaga counties.

ii. To assess the influence of teacher's expectations on the performance of students academically in public secondary schools in Nyeri and Kirinyaga counties.

iii. To investigate the influence of incentives on the performance of students academically in public secondary schools in Nyeri and Kirinyaga counties. 
Table 1. Positive Teacher - Student Relationship and Academic Performance

\begin{tabular}{|c|c|c|c|c|c|c|}
\hline \multirow[b]{2}{*}{ Response } & \multicolumn{2}{|c|}{ Principals / Teachers } & \multicolumn{4}{|c|}{ Students } \\
\hline & Frequency & Percent & Cumulative $\%$ & Frequency & Percent & Cumulative $\%$ \\
\hline Strongly Agree & 20 & 37.0 & 37.0 & 146 & 39.5 & 39.5 \\
\hline Agree & 29 & 53.7 & 90.7 & 167 & 45.1 & 84.1 \\
\hline Undecided & 0 & 0 & 90.7 & 30 & 8.1 & 92.7 \\
\hline Disagree & 5 & 9.3 & 100.0 & 27 & 7.3 & 100.0 \\
\hline Total & 54 & & & 370 & & \\
\hline
\end{tabular}

Table 2. Teacher expectations and academic performance

\begin{tabular}{|c|c|c|c|c|c|c|}
\hline \multirow[b]{2}{*}{ Response } & \multicolumn{2}{|c|}{ Principals / Teachers } & \multicolumn{4}{|c|}{ Students } \\
\hline & Frequency & Percent & Cumulative \% & Frequency & Percent & Cumulative \% \\
\hline Strongly Agree & 17 & 31.50 & 31.5 & 66 & 17.8 & 17.8 \\
\hline Agree & 20 & 37.0 & 68.5 & 172 & 46.5 & 64.3 \\
\hline Undecided & 17 & 31.5 & 100 & 132 & 35.7 & 100 \\
\hline Total & 54 & & & 370 & & \\
\hline
\end{tabular}

\section{METHODOLOGY}

The study used a descriptive survey research design. This design allowed for the investigation of the educational problems through the attainment of facts and opinions concerning the current conditions of the variables. Questionnaires were used to collect data from selected respondents from Nyeri and kirinyaga counties. Reliability of the questionnaires was tested through a pilot study. The researcher visited the sampled schools and administered the questionnaires. The completed questionnaires were collected after a week. This study considered all form three learners, form three teachers and principals in the 270 public secondary schools with form three classes in Nyeri and Kirinyaga Counties. The target population was 270 principals 270 teachers and 9980 form three students. The researcher applied stratified sampling to select 27 schools, nine girls' schools, nine boys' schools and nine mixed secondary schools from the 270 public secondary schools in Nyeri and Kirinyaga counties. Gay's formula of 10\% was be used to select 27 principals and purposively sampled 27 class teachers of the sampled schools. The table of Krejcie and Morgan was used to select 370 student. Simple random sampling was used. The data was analyzed with the help of SPSS version 19. The analyzed data was represented in table form in line with the study objectives

\section{RESULTS AND DISCUSSION}

The results and discussion are presented in accordance with the objectives of the study.

i. The first objective sought to establish the influence of positive teacher- student relationship on academic performance of students in secondary schools in Nyeri and Kirinyaga counties.

The respondents were issued with questionnaires and were required to indicate their responses to the statements and to express how much they agree or disagree with a particular statement. The findings are presented on Table 1.

Data analysis revealed that majority $90.7 \%$ of the teachers agreed that a positive teacher-student relationship boosted academic performance while $9.3 \%$ disagreed whereas $84.6 \%$ of the students agreed and $7.3 \%$ disagreed that a positive relationship with their teachers improved their academic performance. The study found that a positive teacher-student relationship influenced academic performance findings which agreed with Murray and Malmgren (2005) that having positive teacher-student relationships is critical in enhancing the students' higher levels of self-efficacy in their academics, self-esteem and higher confidence levels in their employment outcomes in the future. Migley et al. (1989) also noted that the awareness of the presence of a caring teacher, impacted the academic achievement of those students that are considered high risk for high school dropout. Furthermore, their study also noted that for those students who moved from elementary school that had low teacher-student closeness to middle school that had a high teacher-student closeness, considerably increased in their math skills.

ii. The second objective sought to assess the influence of teacher's expectations on subsequent student academic performance of students in public secondary schools in Nyeri and Kirinyaga counties. The respondents were issued with questionnaires and were required to indicate their responses to the statements and to express how much they agree or disagree with a particular statement. The findings are presented on Table 2. 
Table 3. Rewards and Academic Performance

\begin{tabular}{|c|c|c|c|c|c|c|}
\hline \multirow[b]{2}{*}{ Response } & \multicolumn{2}{|c|}{ Principals / Teachers } & \multicolumn{4}{|c|}{ Students } \\
\hline & Frequency & Percent & Cumulative $\%$ & Frequency & Percent & Cumulative $\%$ \\
\hline Strongly Agree & 35 & 64.8 & 64.8 & 118 & 31.9 & 31.9 \\
\hline Agree & 9 & 16.7 & 81.5 & 202 & 54.6 & 86.5 \\
\hline Undecided & 10 & 18.5 & 100 & 0 & 0 & 86.5 \\
\hline Disagree & 0 & 0.0 & 0 & 50 & 13.5 & 100 \\
\hline Strongly Disagree & 0 & 0.0 & 0 & 0 & 0 & \\
\hline Total & 54 & 100.0 & & 370 & 100.0 & \\
\hline
\end{tabular}

Data presented in Table 2 showed that $68.5 \%$ of the teachers agreed whereas another $31.5 \%$ were undecided. Analysis of students' responses indicated that $64.3 \%$ agreed while $35.7 \%$ of the students were undecided. The study found out that students were highly motivated as they sought to meet their teacher's expectations which resulted to better performance. The findings concurred with Henry et al. (2012) that motivation is closely linked to student's perception of teacher expectations.

iii. The third objective sought to investigate the influence of incentives on student academic performance of students in public secondary schools in Nyeri and Kirinyaga counties. The respondents were issued with questionnaires and were required to indicate their responses to the statements and to express how much they agree or disagree with a particular statement. The findings are presented on Table 3.

Data showed that all 81.5\% teachers agreed that rewarding students improved their academic performance while $18.5 \%$ were undecided. $86.5 \%$ of students agreeing to the statement that rewards boosted their academic performance. Data also showed that $13.5 \%$ of the students disagreed with the statement that rewards boosted academic performance. The study found out that rewards played a key role in improving academic performance of learners and should be emphasized by all teachers. The findings by Migley et al. (1989) that rewards play a key role in student motivation proved that teachers should invest in diverse rewards in order to motivate learners. Rewards they noted did not necessary involve monetary gifts but also recognition and special privileges in class can boost academic performance of learners

\section{CONCLUSION}

One of the key findings is that positive bond between teachers and students is the most effective motivational technique. The other major finding is that giving rewards which are also referred to as incentives is a major factor for good academic performance. This incentive may be a material object or an intangible one such as giving praise for correct outcomes. The study also revealed that high teacher expectations of student ability influenced subsequent student academic performance, and made them feel motivated to perform better. Therefore the study concluded that student motivation by teachers has a positive influence on academic performance.

\section{RECOMMENDATIONS}

The study recommended that since most of the learning occurred inside the classroom and that teachers played an important role in motivating students, positive teacher- student relationship should be enhanced to enable all students to learn at a high standard. It further recommended that since rewards played a key role in improving academic performance of learners, they should be emphasized by all teachers. The study also recommended that teachers should motivate their learners by spelling out high expectations on their students' ability since it is also a vital factor on students' performance academically.

\section{REFERENCES}

Athman and Monroe. (2004). The effects of environment-based education on students achievement motivation. Available at: http://www.seer,org/pages/research/JIR

Ayub. (2010). The relationship between self- concept and satisfaction with life among adolescents. International Journal of Interdisciplinary Social Sciences, 5(4). https://doi.org/10.18848/1833-1882/CGP/v05i04/51663

Baker, Grant and Morlock (2008). The teacher-student relationship as a development context for children internalizing behavior problems. Quarterly, 23(1), 13-1.

Covington, M. V. (2000). Goal theory motivation and school achievement. An Integrative Review of Psychology, 51, $171-200$. 
Deci, E. L., Vallernad, R. J., Pelletier, L. G. and Ryans, R. M. (1991). Motivation and Education: The Self Determination Perspective. Education Psychologist, 29(3), 4.

Elliot, A. J. and Dwerk, C. S. (2005). Handbook of competence and motivation. New York: Guilfort Press.

Gallagher, E. (2013). The Effects of Teacher-Student Relationships: Social and Academic Outcomes of LowIncome Middle and High School Students.

Hamre, B. K. and Pianta, R. C. (2001). Early Teacher-Child Relationships and the Trajectory of Children's School Outcomes through Eighth Grade. Child Development, 72(2), 625-638. https://doi.org/10.1111/1467-8624.00301

Henry, K. L., Knight, K. E. and Thornberry, T. P. (2012). School Disengagement as a Predictor of Dropout, Delinquency, and Problem Substance Use during Adolescence and Early Adulthood. Journal of Youth and Adolescence, 41(2), 156-166. https:// doi.org/10.1007/s10964-011-9665-3

Kusereka, L. G. (2003). Factors Influencing the Motivation of Zimbabwean Secondary Teachers: An Educational Management Perspective. Unpublished Master's Dissertation, University of South Africa.

McKinney. (2000). Available at: http:// citeseerx1st.psu.edu/viewdoc/download?doi=10.1.1572.7163\&rep=rep1

Migley, C., Feldlaufer, H. and Eccles, J. S. (1989). Student/Teacher Relations and Attitudes toward Mathematics before and after the Transition to Junior High School. Child Development, 10(5), 981-992. https://doi.org/10.2307/1131038

Miheso, K. M. (2012). Factors affecting mathematics performance among secondary school students in Nairobi province. PhD Thesis Kenyatta University. http:/ /ir-libraryku.ac.ke/etdhandle123456789/2485

Murray, C. and Malmgren, K. (2005). Implementing a teacher-student relationship program in a high-poverty urban school: Effects on social, emotional, and academic adjustment and lessons learned. Journal of School Psychology, 43(2), 137-152. https:// doi.org/10.1016/j.jsp.2005.01.003

MOEST. (2005). Sessional paper No. 1 of 2005 on policy. Framework for Education, Training and Research.

Mitchell. (1992). The relationship between classroom motivation and academic achievement in first and third Grade. P.7.

Ngeno and Changeiywo. (2007). The learning environment. Available at: http://www.researchgate.net/publication/22883774519

Okagaki, L. and Frensch, P. A. (2006). Parenting and Children's School Achievement: A Multiethnic Perspective. American Educational Research Journal, 35(2), 123-144.

Ryan, R. M. and Deci, E. L. (2000). Self-Determination Theory and the facilitation of intrinsic motication, social development and well-being. American Psychologist, 55(1), 68-78.

Standardmedia.co.ke. (2014). KCSE 2013: Countries order of merit: Kenya. The standard. Available at: https://standardmedia.co.ke

Tenenbaum, H. R. and Ruck, M. D. (2007). Are Teachers' Expectations Different for Racial Minority than for European American Students? A Meta-Analysis. Journal of Educational Psychology, 99(2), 253-273. https:// doi.org/10.1037/0022-0663.99.2.253

Wells. (2000). Intrinsic motivation and environmental factors. Educational Gerontology, 36(3), 229-243. https://doi.org/10.1080/03601270903182901

Wentzel, K. R. (2003). Socio-Metric Status and Adjustment in Middle school: A Longitudinal Study. The Journal of Early Adolescence, 23(1), 5-28. https:/ / doi.org/10.1177/0272431602239128

Williams, K. C. and Williams, C. C. (2002). Five Key Ingredients for Improving Student Motivation. California. Carlifornia University Press. 